Article

\title{
Design and Validation of an Instrument to Evaluate the Learning Acquired by Nursing Students from a Brief Tobacco Intervention (BTI-StC)
}

\author{
Antonio Jesús Ramos-Morcillo ${ }^{1}{ }^{\mathbb{D}}$, César Leal-Costa ${ }^{1, * \mathbb{D}}$, Ana Teresa García-Moral ${ }^{2}$, \\ Rafael del-Pino-Casado ${ }^{3}$ (D) and María Ruzafa-Martínez ${ }^{1}$ \\ 1 Department of Nursing, Faculty of Nursing, University of Murcia, 30100 Espinardo, Spain; \\ ajramos@um.es (A.J.R.-M.); maruzafa@um.es (M.R.-M.) \\ 2 Jaén Nordeste Sanitary District, Regional Ministry of Health of the Andalusian Regional Government, \\ Úbeda, 23400 Jaén, Spain; tec.promocion.salud.ajaene.sspa@juntadeandalucia.es \\ 3 Department of Nursing, School of Health Sciences, University of Jaén, 23071 Jaén, Spain; rdelpino@ujaen.es \\ * Correspondence: cleal@um.es
}

Received: 21 September 2019; Accepted: 14 October 2019; Published: 16 October 2019

\begin{abstract}
The aim of this study was to design and validate an instrument, based on the WHO 5As+5Rs model, to test the acquisition by nursing students of a brief tobacco intervention (BTI) learning. A validation design of an instrument following the criterion referenced tests model using videos of simulated BTIs in the primary care setting was carried out. The study included 11 experts in smoking prevention/care and 260 second-year nursing students. The study was in two stages: (1) selection and recording of clinical simulations (settings), and (2) test construction. Content was validated by applying the Delphi consensus technique and calculating the Content Validity Ratio (CVR) and Content Validity Index (CVI). A pilot test was conducted for item analysis. Reliability was evaluated as internal consistency (Kuder-Richardson [KR-20]) and test-retest temporal stability (intraclass correlation coefficient [ICC]). Three simulation settings were recorded. An instrument $\left(\mathrm{BTI}-\mathrm{St}{ }^{\circledR}\right)$ was developed with 23 items for dichotomous (yes/no) response. CVR was $>70 \%$ for all items, KR-20 of $0.81-0.88$, and ICC between 0.68 and $0.73(p<0.0001)$. The BTI-St ${ }^{\circledR}$ is a robust and reliable instrument that is easily and rapidly applied. It follows the WHO 5As+5Rs model and offers objective criterion-referenced evaluation of BTI learning in nursing students.
\end{abstract}

Keywords: brief advice; smoking cessation; tobacco sse cessation; validation studies; counseling; criterion referenced tests; tobacco cessation; 5As; student; nursing students

\section{Introduction}

Smoking is a major public health threat that annually claims the lives of around 6 million smokers [1] and is the main avoidable cause of premature death worldwide [2]. It is estimated to be responsible for $71 \%$ of lung cancers, $42 \%$ of chronic respiratory diseases, and $10 \%$ of cardiovascular diseases [3]. The prevalence of smoking remains at over $20 \%$ in high-income countries [4], and the WHO has developed a wide-reaching program to eradicate this habit, including the MPOWER anti-smoking package for a brief tobacco intervention (BTI) in primary care [5]. This intervention has proven effective when provided by physicians, nurses, and dentists [6-8], can be readily adopted by health care institutions [9], and is considered cost-effective over the long term [10].

However, although simple and effective interventions are available, their application is not assured. Thus, a systematic review showed that only $65 \%$ of family physicians asked patients about their tobacco habit and only $63 \%$ advised them to quit [11]. A study of 3482 American nurses found that $73 \%$ asked about patients' tobacco consumption and only $62 \%$ recommended its cessation [12]. A meta-analysis 
of 15 studies carried out in the USA, Canada, and four European countries [13] concluded that nurses mainly ask about tobacco consumption and less frequently assist with quitting (5-52\%) or arrange a follow-up program with the patient (3-26\%). It found that nurses who smoked were $13 \%$ less likely to advise their patients to quit and $25 \%$ less likely to organize a follow-up of smoking cessation. The training of professionals on this issue is crucial to increase the implementation of brief tobacco interventions (BTIs). A meta-analysis showed that professionals trained in these interventions are more likely to implement anti-tobacco measures [14]. In fact, the WHO called for education on BTIs to be included in the curricula of Schools of Health Science [15].

\section{Background}

Various methods have been used to facilitate BTI learning [16,17]. These are mostly based on the 5As+5Rs model of the US Public Health Service [18] and WHO [19], in which the intervention follows a sequence of five counseling strategies: "Ask" (ask all patients about tobacco use), "Advise" (advise all tobacco users to quit), "Assess" (assess the readiness to quit), "Assist" (assist with quitting), and "Arrange" (arrange follow-up). The "Assist" option includes the 5Rs: "Relevance", "Risks", "Rewards", "Roadblocks", and "Repetition".

Various approaches have been adopted to test the learning acquired after BTI training, including: multiple-choice tests [20], self-reports [21], patient reports with peer evaluation by health care professionals [22], evaluation by experts using videotaped objective structured clinical examinations (VOSCEs) [16], and evaluation by experts based on direct observations of real encounters and objective structured clinical examinations (OSCEs) [23]. The selection of the most appropriate model depends on the purpose of the evaluation [23].

Criterion-referenced tests (CRTs) have been little used in this context, but their characteristics and objectives make them of special interest. They serve to monitor the progress of students, objectively confirm their performance, diagnose learning deficits, and evaluate educational programs [24]. No standardized and validated CRT is yet available to assess the acquisition of BIT learning; therefore, the objective of this study was to design and validate a CRT based on the $5 \mathrm{As}+5 \mathrm{Rs}$ model in a population of nursing students.

\section{Materials and Methods}

A two-stage study (Figure 1) was conducted between February 2017 and January 2019 to develop and then validate a CRT to evaluate BIT learning, comparing test results with standards previously established by the expert group [25].

Stage 1: Creation and recording of BTI simulations in different settings and the establishment of evaluation standards. The selection of experts was based on three criteria: (a) variability in their professional profiles; (b) clinical competence and experience of providing patients with anti-tobacco advice; (c) experience of training professionals on this issue. Eleven experts working in the Spanish public health service ( 2 physicians, 2 nurses, and 7 psychologists) were selected, all with more than 10 years' experience of smoking-related care in a community setting. This group consensually defined the learning aspects to be evaluated, explored the application of the 5As+5Rs model, and developed and selected typical clinical settings with different outcomes and problems for video recording.

Stage 2: The development of the CRT was similar to proposals by Hambleton and Rogers [26] and structured in the following four phases: 


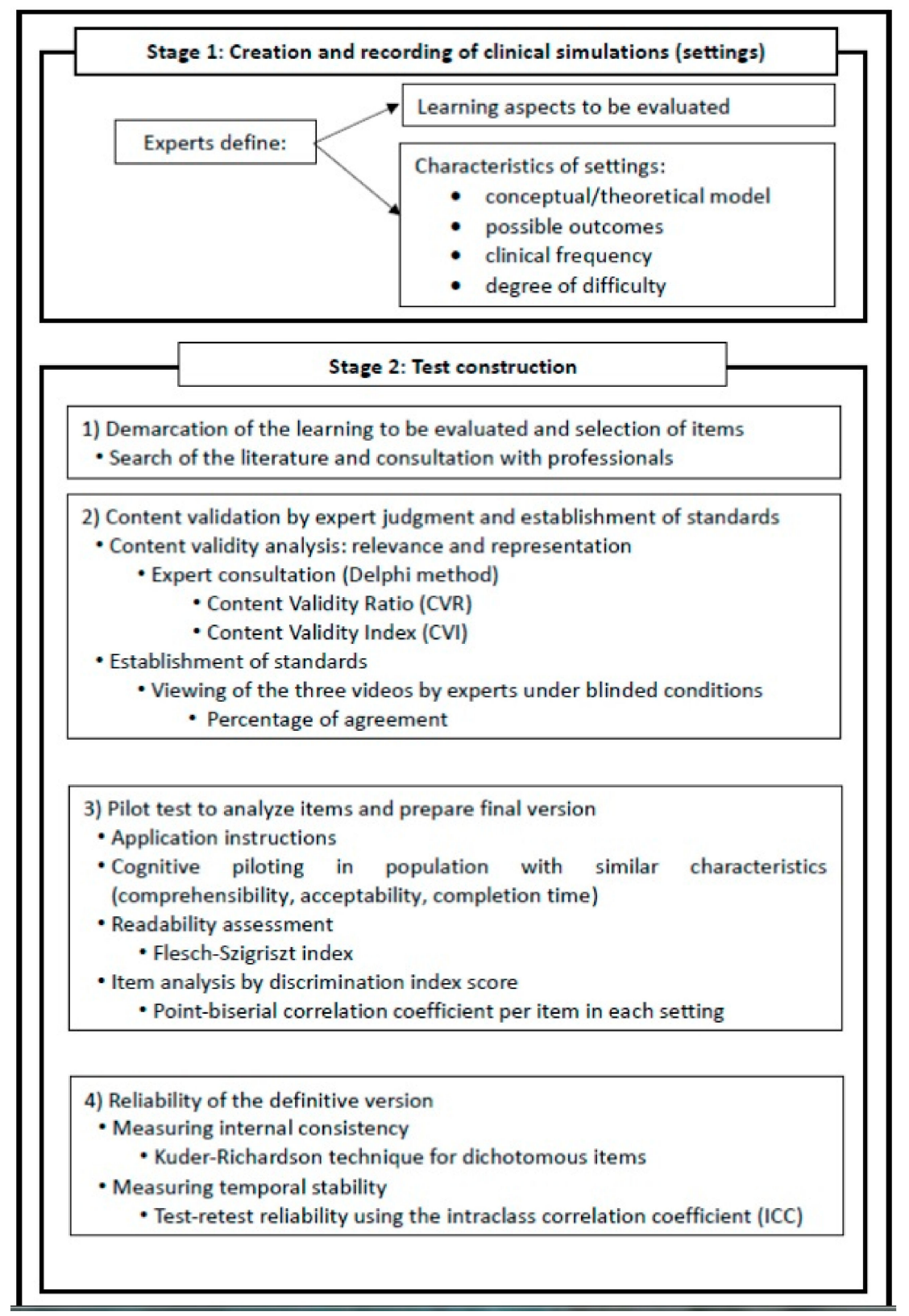

Figure 1. General diagram of the study: process of questionnaire development.

Phase 1: Demarcation of the learning evaluated and selection of items.

The expert group selected the theoretical model to be followed and defined behaviors that would indicate BTI learning acquisition. A search of MEDLINE, CINAHL, and SciELO databases was conducted to identify items for inclusion, using the terms "survey", "brief intervention", and "tobacco" and including all studies in English or Spanish up to June 2018. The final selection was then made, only including studies on instruments to evaluate BTI learning in health science professionals and/or students.

Phase 2: Content validation by expert judgment and establishment of standards.

Based on the draft developed in phase 1, the expert group used the Delphi consensus technique to assess the adequacy, relevance, and readability of each item on a 5-point Likert scale. The final selection of items was determined according to their Content Validity Ratio (CVR > 0.70), and the Content Validity Index (CVI) was calculated for the whole instrument (CVI > 0.80). Members of the expert group were also asked for any proposals to improve the instrument. Evaluation standards were established by the experts after each had viewed the simulations in three settings and evaluated the 
intervention in a blinded manner, followed by the calculation of the percentage of items with identical responses from all experts. The acquired learning was scored as the percentage of correct responses according to the standard established in each setting.

Phase 3: Pilot test to analyze items and prepare final version.

Instructions for the pilot test and the scoring criteria were based on the instrument developed in phase 2. First, cognitive piloting was conducted in a group of 10 second-year nursing students to assess the comprehensibility, acceptability, and completion time for each setting. Readability was assessed with the Flesch-Szigriszt index [27] using INFLESZ software and classifying scores as follows: $<40=$ very difficult, $40-55=$ somewhat difficult, $55-65=$ normal, $65-80=$ rather easy, and $>80=$ very easy.

Next, a pilot test was conducted in a group of 160 second-year nursing students, half with BTI training, who viewed and responded to the three videos. Second-year students were selected because it is the first year in which they would receive training related to anti-tobacco interventions in the nursing degree course of the University of Murcia. The instrument was administered under the same conditions as intended for its clinical application. Results were used to calculate the point-biserial correlation coefficient (discrimination index) per item in each setting, considering values $>0.30$ to be adequate.

Phase 4: Evaluation of the reliability of the definitive instrument.

The definitive version of the test was administered to a group of 100 second-year nursing students who had not participated in the pilot tests. Its reliability was determined by using the Kuder-Richardson technique for internal consistency and the test-retest method, repeating the test on 33 participants after a 14-day interval and calculating the intraclass correlation coefficient (ICC) with $95 \%$ confidence interval (CI).

\section{Ethical Considerations}

All participants gave their consent to participate in the study, which was approved by the Research Ethics Committee of the University of Murcia (ID: 1968/2018).

SPSS Statistics for Windows, version 23.0. (IBM Corp, Armonk, NY, USA) was used for the data analysis, applying the tests reported above.

\section{Results}

\subsection{Stage 1}

We recorded three videos of around $2.5 \mathrm{~min}$ in duration. Each video (setting) simulated a BTI involving a primary healthcare professional and patient, with different outcomes and including various pitfalls (e.g., unstructured/non-systematic BTI, failure to record clinical history, and non-personalized advice). The three possible outcomes in the 5 As +5 Rs model are that the patient quits smoking, is willing to make an attempt to quit smoking, or is not willing to make this attempt. Given that the first outcome is not controversial, the second outcome was simulated in settings 1 and 2 and the third in setting 3 , including different pitfalls.

\subsection{Stage 2}

\subsubsection{Phase 1: Demarcation of Evaluated Learning and Item Redaction}

The instrument was designed in accordance with the 5 As+5Rs model $[17,18]$. In the literature search, 393 records were retrieved from MEDLINE, and 32 of these were selected after reading their titles and abstracts; 58 and 12 different records were retrieved from CINALH and SciELO respectively, but none were selected. After a reading of the full texts, 14 studies were finally chosen: three on instrument validation and 11 on BTI learning evaluation (Table S1). After reading these studies, 15 items were chosen and adapted to the instrument, and further items were redacted to complete 
the theoretical model. The instrument was organized into five sections (5As) with a total of 24 items. After viewing the videos, students responded to each dichotomous (yes/no) item on the performance of the professional.

\subsubsection{Phase 2: Content Validation by Expert Judgment and Establishment of Standards}

After the first expert round, low CVRs were obtained for adequacy (items 4, 16, 20, and 24), relevance (items 4 and 24), and readability (items 4, 8, 12, and 24) (Figure S1). These items were re-written for the second expert round, in which they all achieved a CVR $>70 \%$ except for item 24 ("The evaluation of willingness to quit smoking is repeated"), which was therefore eliminated. The final BTI-St ${ }^{\odot}$ contained 23 items and obtained a CVI of 0.84 . For the procedure to establish standards, the percentage of responses on which the experts were unanimous was $94.5 \%$ for responses in settings 1 and 2, which were resolved with the response to 11 items (Figure S1: items 5-15) and 98.2\% in setting 3, which was resolved with the response to 15 items (Figure S1: items 5-11, 16-23). There was disagreement between two experts on the response to item 6 in setting 1, item 10 in setting 2, and item 11 in all three settings. The experts proposed that the test should follow an algorithmic rather than linear format (Figure S1).

\subsubsection{Phase 3: Pilot Test to Analyze Items and Prepare Final Version}

No items were modified after assessing the results of the pilot test and its comprehensibility and acceptability. The time to complete the test was $2.5 \mathrm{~min}$ in each setting. The instrument obtained a Flesch-Szigriszt index score of 58.04, indicating normal readability. A discrimination index score $>0.30$ was achieved by all items in all three settings, indicating adequate discrimination (Table 1).

Table 1. Results of discrimination analysis of brief tobacco intervention (BTI)-St items in the three settings.

\begin{tabular}{|c|c|c|c|}
\hline & Setting 1 & Setting 2 & Setting 3 \\
\hline (BTI)-St Items & $\begin{array}{l}\text { Corrected Item-Total } \\
\text { Correlation }\end{array}$ & $\begin{array}{l}\text { Corrected Item-Total } \\
\text { Correlation }\end{array}$ & $\begin{array}{l}\text { Corrected Item-Total } \\
\quad \text { Correlation }\end{array}$ \\
\hline Item 5 Classifying the person as a smoker & 0.46 & 0.34 & 0.35 \\
\hline $\begin{array}{l}\text { Item } 6 \text { Recording this information in their } \\
\text { clinical history }\end{array}$ & 0.48 & 0.40 & 0.69 \\
\hline Item 7 Clearly offering advice & 0.40 & 0.35 & 0.64 \\
\hline Item 8 Assertively offering advice & 0.55 & 0.45 & 0.64 \\
\hline Item 9 Offering advice in a personalized manner & 0.52 & 0.46 & 0.63 \\
\hline $\begin{array}{l}\text { Item } 10 \text { Assessing whether they would like to be } \\
\text { a non-smoker }\end{array}$ & 0.48 & 0.32 & 0.31 \\
\hline $\begin{array}{l}\text { Item } 11 \text { Assessing whether the person thinks they } \\
\text { can quit smoking }\end{array}$ & 0.31 & 0.32 & 0.30 \\
\hline $\begin{array}{l}\text { Item } 12 \text { Providing motivation based on the } \\
\text { importance of quitting for the person }\end{array}$ & 0.59 & 0.67 & \\
\hline Item 13 Reporting the risks of smoking for the person & 0.60 & 0.50 & \\
\hline $\begin{array}{l}\text { Item } 14 \text { Asking the person to identify the benefits of } \\
\text { quitting that they consider important }\end{array}$ & 0.55 & 0.65 & \\
\hline $\begin{array}{l}\text { Item } 15 \text { Asking the person to identify the } \\
\text { barriers/obstacles to quitting }\end{array}$ & 0.63 & 0.57 & \\
\hline $\begin{array}{l}\text { Item } 16 \text { Indicating a date to quit smoking (preferably } \\
\text { within } 2 \text { weeks) }\end{array}$ & & & 0.53 \\
\hline $\begin{array}{l}\text { Item } 17 \text { Indicating the need to communicate the } \\
\text { quitting attempt to family, workmates, and friends } \\
\text { and to ask them for help }\end{array}$ & & & 0.58 \\
\hline $\begin{array}{l}\text { Item } 18 \text { Indicating the need to anticipate difficulties } \\
\text { (situations that can hamper quitting) }\end{array}$ & & & 0.58 \\
\hline $\begin{array}{l}\text { Item } 19 \text { Recommending the person to make his/her } \\
\text { house a tobacco-free environment }\end{array}$ & & & 0.59 \\
\hline $\begin{array}{l}\text { Item } 20 \text { Describing the availability of } \\
\text { pharmacological treatments if appropriate }\end{array}$ & & & 0.43 \\
\hline $\begin{array}{l}\text { Item } 21 \text { Offering complementary materials } \\
\text { (brochures, quit line, etc.) }\end{array}$ & & & 0.51 \\
\hline Item 22 Agreeing on a follow-up contact & & & 0.44 \\
\hline $\begin{array}{l}\text { Item } 23 \text { Referring the person to specialized resources } \\
\text { for quitting (if available) }\end{array}$ & & & 0.60 \\
\hline
\end{tabular}




\subsubsection{Phase 4: Reliability of the Definitive Version}

The test demonstrated adequate reliability, obtaining KR-20 values of 0.81 in setting 1 (11 items), 0.86 in setting 2 (11 items), and 0.88 in setting 3 (15 items), and ICC (test-retest) values of $0.73(95 \%$ $C I=0.44-0.86 ; p<0.001)$ in setting $1,0.68(95 \% C I=0.35-0.84 ; p<0.001)$ in setting 2 , and $0.82(95 \%$ $\mathrm{CI}=0.63-0.91 ; p<0.001)$ in setting 3 .

\section{Discussion}

This study describes the development and validation of an instrument to evaluate BTI learning in nursing students using videos of standardized clinical situations. To our best knowledge, BTI-St ${ }^{\circledR}$ is the first CRT-based instrument on BTI learning and allows the detection of learning deficits and the implementation of remedial measures.

Although the creation and video-recording of simulations is time-consuming and requires the services of experts, this method allows performance variations to be attributed to the learning of students rather than the characteristics of cases [28]. This approach has previously been adopted in the training of nursing students, although evaluations have required the participation of experts [29] or the employment of subjective self-evaluation questionnaires [30].

The BTI-St $\odot$ is based on the 5 As+5Rs model, which has been used in most research on instruments to that evaluate the BTI learning of health care professionals and students $[18,19,21,31-33]$. The consensus of our expert group on the final version of the instrument confirms the relevance of the items selected [34]. Only one item was eliminated because it referred to repeated evaluations of the readiness to quit smoking, and all three settings simulated a first visit alone. The items obtained satisfactory discrimination values, demonstrating that the scores are valid indicators of BTI learning. Scores at the minimum threshold were obtained for Item 10 in settings 2 and 3 and for item 11 in all settings. There was also some discrepancy among the experts for item 11 (Assessing whether the person thinks they can quit smoking), probably because this aspect was less clearly shown in the videos. The internal consistency of the instrument was found to be adequate, obtaining values $>0.80$ in each setting, and the test-retest temporal stability ranged between moderate (ICC of 0.68 ) in setting 2 and high (0.82) in setting 3. In addition, testing of the instrument in three different clinical scenarios with distinct contents further supported the reliability of its results.

The definitive version of the instrument was found to be comprehensible and acceptable by the students, and its readability is normal according to the Inflesz scale; therefore, no rewriting is needed. Furthermore, its application requires very little time, around 2.5 minutes to watch the video plus 2 minutes to respond to the questionnaire.

The WHO recommends the assessment of BTI learning for health care professionals and students [15], but this has been carried out in less than half of the numerous programs taught on nursing courses [35]. It is crucial to determine the effectiveness of learning because this allows the introduction of improvements, the comparison of different approaches, and detection of variations among distinct types of trainee [36].

The BTI-St $($ is based on the $5 \mathrm{As}+5 \mathrm{Rs}$ model, whereas some authors have used unconsolidated models [16,37], have only partially followed the 5As model [32,38], or have not reported the model used [39]. Our instrument also has the advantage of greater objectivity in comparison to the self-evaluation approach that has been employed in many studies [20,21,31,32,39]. Methods that depend on expert evaluations using VOSCE or OSCE rubrics have also been limited by a failure to test their validity $[16,22,37,40]$ or their validity and reliability [33] (Table S1).

BTI-St $($ C can be useful in various teaching and evaluation approaches, including high-fidelity clinical simulations that contain an experiential component and a reflexive element, as in post-simulation debriefing [41] and it can also complement expert OSCE and VOSCE evaluations. 


\section{Limitations}

We did not determine the convergent validity of the BTI-StC with respect to a different independent instrument. It would also be of interest to explore the impact of an educational intervention on BTI learning. The present results were obtained in nursing undergraduates, and the validity of this instrument should also be tested in other students of health sciences. Finally, BTI-St@ only evaluates the brief intervention itself. It takes no account of the communication quality or the generally long-term nature of primary care, the most frequent setting for this type of intervention.

\section{Conclusions}

BTI-StC is a robust and reliable instrument that can be simply and rapidly applied. It follows the WHO 5As+5Rs model and offers a more objective criterion-referenced evaluation of BTI learning in nursing students. BTI-StC can be used to evaluate the effectiveness of different educational interventions, facilitating the diagnosis of deficits in the learning of any of the five As.

Supplementary Materials: The following are available online at http://www.mdpi.com/1660-4601/16/20/3944/s1, Figure S1: Brief Tobacco Intervention (BTI-St $\left.{ }^{(}\right)$, Table S1: Comparison of instruments to measure anti-tobacco advice.

Author Contributions: Conceptualization, A.J.R.-M. and M.R.-M.; methodology, A.J.R.-M., M.R.-M., R.D.-P.-C. and C.L.-C.; software, A.J.R.-M., C.L.-C.; validation, A.J.R.-M., M.R.-M., R.D.-P.-C, A.T.G.-M. and C.L.-C.; formal analysis, A.J.R.-M., M.R.-M, R.D.-P.-C., C.L.-C. and A.T.G.-M.; investigation, A.J.R.-M., A.T.G.-M.; resources, A.J.R.-M., M.R.-M., C.L.-C.; data curation, M.R.-M., C.L.-C.; writing-original draft preparation, M.R.-M., A.J.R.-M., A.T.G.-M.; writing-review and editing, A.J.R.-M., M.R.-M., R.D.-P.-C., A.T.G.-M. and C.L.-C; visualization, A.J.R.-M. and M.R.-M.; supervision, A.J.R.-M. and M.R.-M.; project administration, A.J.R.-M. and M.R.-M.

Funding: This research received no external funding.

Acknowledgments: -We thank all the students' participants for the selfless time dedicated to this investigation. Our thanks to the experts who participated in this research.

Conflicts of Interest: The authors declare no conflict of interest.

\section{References}

1. Oberg, M.; Jaakkola, M.S.; Woodward, A.; Peruga, A.; Prüss-Ustün, A. Worldwide burden of disease from exposure to second-hand smoke: A retrospective analysis of data from 192 countries. Lancet 2011, 377, 139-146. [CrossRef]

2. Eriksen, M.; Mackay, J.; Schluger, N.; Islami, F.; Drope, J. The Tobacco Atlas, 5th ed.; American Cancer Society: Atlanta, GA, USA, 2015.

3. WHO. Global Status Report on Noncommunicable Diseases 2010; WHO: Geneva, Switzerland, 2011.

4. WHO. WHO Report on the Global Tobacco Epidemic: Monitoring Tobacco Use and Prevention Policices; WHO: Geneva, Switzerland, 2017.

5. WHO. MPOWER: A Policy Package To Reverse The Tobacco Epidemic; WHO: Geneva, Switzerland, 2008; ISBN 978-92-4-159663-3.

6. Carr, A.B.; Ebbert, J. Interventions for tobacco cessation in the dental setting. Cochrane Database Syst. Rev. 2012, CD005084. [CrossRef] [PubMed]

7. Rice, V.H.; Hartmann-Boyce, J.; Stead, L.F. Nursing interventions for smoking cessation. Cochrane Database Syst. Rev. 2013, 8, CD001188. [CrossRef] [PubMed]

8. Silagy, C. Physician advice for smoking cessation. Cochrane Database Syst Rev 2000, CD000165. [CrossRef]

9. West, R.; Raw, M.; McNeill, A.; Stead, L.; Aveyard, P.; Bitton, J.; Stapleton, J.; McRobbie, H.; Pokhrel, S.; Lester-George, A.; et al. Health-care interventions to promote and assist tobacco cessation: A review of efficacy, effectiveness and affordability for use in national guideline development. Addiction 2015, 110, 1388-1403. [CrossRef] [PubMed]

10. Lopez-Nicolas, A.; Trapero-Bertran, M.; Munoz, C. Cost-benefit of medical advice for quitting smoking in the Region of Murcia. Aten. Primaria 2017, 49, 407-416. [PubMed]

11. Bartsch, A.-L.; Harter, M.; Niedrich, J.; Brutt, A.L.; Buchholz, A. A Systematic Literature Review of Self-Reported Smoking Cessation Counseling by Primary Care Physicians. PLoS ONE 2016, 11, e0168482. [CrossRef] 
12. Sarna, L.; Bialous, S.A.; Wells, M.; Kotlerman, J.; Wewers, M.E.; Froelicher, E.S. Frequency of nurses' smoking cessation interventions: Report from a national survey. J. Clin. Nurs. 2009, 18, 2066-2077. [CrossRef] [PubMed]

13. Duaso, M.J.; Bakhshi, S.; Mujika, A.; Purssell, E.; While, A.E. Nurses' smoking habits and their professional smoking cessation practices. A systematic review and meta-analysis. Int. J. Nurs. Stud. 2017, 67, 3-11. [CrossRef] [PubMed]

14. Carson, K.V.; Verbiest, M.E.A.; Crone, M.R.; Brinn, M.P.; Esterman, A.J.; Assendelft, W.J.J.; Smith, B.J. Training health professionals in smoking cessation. Cochrane Database Syst. Rev. 2012, CD000214. [CrossRef]

15. WHO. Guidelines for Implementation of Article 12 of the WHO Framework Convention on Tobacco Control; WHO: Geneva, Switzerland, 2010.

16. Hagimoto, A.; Nakamura, M.; Masui, S.; Bai, Y.; Oshima, A. Effects of trained health professionals' behavioral counseling skills on smoking cessation outcomes. Ann. Behav. Med. 2018, 52, 752-761. [CrossRef] [PubMed]

17. Ockene, J.K.; Hayes, R.B.; Churchill, L.C.; Crawford, S.L.; Jolicoeur, D.G.; Murray, D.M.; Shoben, A.B.; David, S.P.; Ferguson, K.J.; Huggett, K.N.; et al. Teaching Medical Students to Help Patients Quit Smoking: Outcomes of a 10-School Randomized Controlled Trial. J. Gen. Intern. Med. 2016, 31, 172-181. [CrossRef] [PubMed]

18. The Clinical Practice Guideline Treating Tobacco Use and Dependence 2008 Update Panel and Staff. A clinical practice guideline for treating tobacco use and dependence: 2008 update: A US Public Health Service report. Am. J. Prev. Med. 2008, 35, 158-176. [CrossRef] [PubMed]

19. World Health Organization. Toolkit for Delivering the 5A's and 5R's Brief Tobacco Interventions in Primary Care; WHO: Geneva, Switzerland, 2014.

20. Kerr, S.; Whyte, R.; Watson, H.; Tolson, D.; McFdyen, A. Smoking Cessation in Later Life: An Evaluation of the Impact of Smoking Cessation Training on the Knowledge, Attitudes and Practice of Members of the Primary Care Team Who Work with Older People. Internet J. Health 2007, 5, 1-10.

21. Newhouse, R.P.; Himmelfarb, C.D.; Liang, Y. Psychometric testing of the smoking cessation counseling scale. J. Nurs. Scholarsh. Off. Publ. Sigma Theta Tau Int. Honor Soc. Nurs. 2011, 43, 405-411. [CrossRef] [PubMed]

22. Romito, L.; Schrader, S.; Zahl, D. Using experiential learning and OSCEs to teach and assess tobacco dependence education with first-year dental students. J. Dent. Educ. 2014, 78, 703-713.

23. Mazor, K.M.; Jolicoeur, D.; Hayes, R.B.; Geller, A.C.; Churchill, L.; Ockene, J.K. Assessing Medical Students' Tobacco Dependence Treatment Skills Using a Detailed Behavioral Checklist. Teach. Learn. Med. 2015, 27, 292-298. [CrossRef]

24. Hambleton, R.K.; Swaminathan, H.; Algina, J.; Coulson, D.B. Criterion-Referenced Testing and Measurement: A Review of Technical Issues and Developments. Rev. Educ. Res. 1978, 48, 1-47. [CrossRef]

25. Pohpham, W. Criterion-Referenced Measurement; Prentice-Hall: Englewood Cliffs, NJ, USA, 1978.

26. Hambleton, R.K.; Rogers, H.J. Advances in criterion-referenced measurement. In Advances in Educational and Psychological Testing: Theory and Applications; Evaluation in education and human services series; Kluwer Academic/Plenum Publishers: New York, NY, USA, 1991; pp. 3-43. ISBN 0-7923-9070-9.

27. Barrio-Cantalejo, I.M.; Simón-Lorda, P.; Melguizo, M.; Escalona, I.; Marijuán, M.I.; Hernando, P. Validation of the INFLESZ scale to evaluate readability of texts aimed at the patient. An. Sist. Sanit. Navar. 2008, 31, 135-152.

28. Hulsman, R.L.; Mollema, E.D.; Oort, F.J.; Hoos, A.M.; de Haes, J.C.J.M. Using standardized video cases for assessment of medical communication skills: Reliability of an objective structured video examination by computer. Patient Educ. Couns. 2006, 60, 24-31. [CrossRef]

29. Koole, S.; Dornan, T.; Aper, L.; De Wever, B.; Scherpbier, A.; Valcke, M.; Cohen-Schotanus, J.; Derese, A. Using video-cases to assess student reflection: Development and validation of an instrument. BMC Med. Educ. 2012, 12, 22. [CrossRef] [PubMed]

30. Coyne, E.; Frommolt, V.; Rands, H.; Kain, V.; Mitchell, M. Simulation videos presented in a blended learning platform to improve Australian nursing students' knowledge of family assessment. Nurse Educ. Today 2018, 66, 96-102. [CrossRef] [PubMed]

31. Corelli, R.L.; Kroon, L.A.; Chung, E.P.; Sakamoto, L.M.; Gundersen, B.; Fenlon, C.M.; Hudmon, K.S. Statewide evaluation of a tobacco cessation curriculum for pharmacy students. Prev. Med. 2005, 40, 888-895. [CrossRef] [PubMed]

32. Delucchi, K.L.; Tajima, B.; Guydish, J. Development of the Smoking Knowledge, Attitudes, and Practices (S-KAP) Instrument. J. Drug Issues 2009, 39, 347-364. [CrossRef] [PubMed] 
33. Wadland, W.C.; WinklerPrins, V.J.; Noel, M.M.; Thompson, M.E.; Ríos-Bedoya, C.F. Student performance on smoking cessation counseling with standardized patients. Fam. Med. 2011, 43, 422-428. [PubMed]

34. Pedrosa, I.; Suárez-Álvarez, J.; García-Cueto, E. Content validity evidences: Theoretical advances and estimation methods. Acción Psicológica 2014, 10, 3-18. [CrossRef]

35. Kruse, G.R.; Rigotti, N.A.; Raw, M.; McNeill, A.; Murray, R.; Piné-Abata, H.; Bitton, A.; McEwen, A. Content and Methods used to Train Tobacco Cessation Treatment Providers: An International Survey. J. Smok. Cessat. 2017, 12, 213-220. [CrossRef]

36. Kerr, S.; Whyte, R.; Watson, H.; Tolson, D.; McFadyen, A.K. A Mixed-Methods Evaluation of the Effectiveness of Tailored Smoking Cessation Training for Healthcare Practitioners Who Work with Older People. Worldviews Evid. Based Nurs. 2011, 8, 177-186. [CrossRef]

37. Ockene, J.; Quirk, M.; Goldberg, R.; Kristeller, J.; Donnelly, G.; Kalan, K.; Gould, B.; Greene, H.; Harrison-Atlas, R.; Pease, J.; et al. A residents' training program for the development of smoking intervention skills. Arch. Intern. Med. 1988, 148, 1039-1045. [CrossRef]

38. Molina, A.J.; Fernández, T.; Fernández, D.; Delgado, M.; de Abajo, S.; Martín, V. Knowledge, attitudes and beliefs about tobacco use after an educative intervention in health sciences' students. Nurse Educ. Today 2012, 32, 862-867. [CrossRef]

39. Sreeramareddy, C.; Suri, S.; Menezes, R.; Kumar, H.; Rahman, M.; Islam, M.R.; Pereira, X.V.; Shah, M.; Sathian, B.; Shetty, U.; et al. Self-reported tobacco smoking practices among medical students and their perceptions towards training about tobacco smoking in medical curricula: A cross-sectional, questionnaire survey in Malaysia, India, Pakistan, Nepal, and Bangladesh. Subst. Abuse Treat. Prev. Policy 2010, 5, 1-9. [CrossRef] [PubMed]

40. Lucas, N.C.C.; Walker, N.; Bullen, C. Using a videotaped objective structured clinical examination to assess Knowledge in Smoking cessation amongst medical Students (the K.I.S.S. Study). Med. Teach. 2016, 38, 1256-1261. [CrossRef] [PubMed]

41. Alhaj Ali, A.; Musallam, E. Debriefing Quality Evaluation in Nursing Simulation-Based Education: An Integrative Review. Clin. Simul. Nurs. 2018, 16, 15-24. [CrossRef]

(C) 2019 by the authors. Licensee MDPI, Basel, Switzerland. This article is an open access article distributed under the terms and conditions of the Creative Commons Attribution (CC BY) license (http://creativecommons.org/licenses/by/4.0/). 